\title{
Evaluation of analgesic and anti-inflammatory activities of ethanolic extract of Cordia sebestena $\mathrm{L}$.
}

\author{
Original Paper \\ Sunaryo H. ${ }^{1,3}$, Siska S. ${ }^{1,3,}$ Hanani E. ${ }^{2,3}$, Anindita RS. ${ }^{3}$, Yanti N. ${ }^{3}$, Lisa ${ }^{3}$ \\ ${ }^{1}$ Department of Pharmacology, Universitas \\ Muhammadiyah Prof. Dr HAMKA, JI. Delima II/IV \\ Klender, Jakarta 13460, Indonesia \\ ${ }^{2}$ Department of Pharmaceutical Biology, Universitas \\ Muhammadiyah Prof. Dr HAMKA, JI. Delima II/IV \\ Klender, Jakarta 13460, Indonesia \\ ${ }^{3}$ Faculty of Pharmacy and Sciences, Universitas \\ Muhammadiyah Prof. Dr HAMKA, Jl. Delima II/IV \\ Klender, Jakarta 13460, Indonesia
}

Received 27 May, 2019, accepted 16 October, 2019

Abstract Trees and shrubs of the genus Cordia are widely distributed in the warmer regions, including Indonesia. The aim of this study was to evaluate the analgesic and anti-inflammatory properties of the ethanolic extract of plant leaves in Wistar albino rats. The analgesic activity was evaluated using the hot plate method and acetic acid-induced writhing, and the anti-inflammatory activity was determined using carrageenan-induced paw oedema. The results showed that the Cordia sebestena ethanol extract $(100,200$ and $400 \mathrm{mg} / \mathrm{kg})$ exhibited significant analgesic effects in a dose-dependent manner in the two pain models tested. The extract also exhibited significant anti-inflammatory effects in the carrageenan-induced inflammation test. The data obtained support the traditional folklore therapeutic claim about its analgesic and anti-inflammatory properties. Nonetheless, further scientific investigation is required to establish its analgesic and anti-inflammatory properties in other experimental models and clinical settings.

Keywords analgesic-anti-inflammatory-carrageenan-Cordia sebestena-hot plate-writhing

\section{INTRODUCTION}

Cordia sebestena L. belongs to the Boraginaceae family, a native plant from the Bahamas to the tip of northern South America, which has been erroneously listed as a Florida native (Osho et al., 2015). C. sebestena L. is an evergreen tree, also known as the Geiger tree, Kou Haole (means a 'foreign plant') in Hawaiian and as 'Geiger' in Indonesia. The plant can grow up to $10 \mathrm{~m}$ tall and cultivated largely in tropical and subtropical areas, where it is widely distributed due to its extensive use in landscaping. The flowers are dark orange in colour, appear as clusters at branch tips, throughout the year, especially in June-July and have a pleasant fragrance. The fruits are oval shaped and green and white in colour (Atolani et al., 2014). This plant originated in Hawaii and has been used as traditional medicine. In Nigeria, C. sebestena is used in traditional medicine for the treatment of gastrointestinal disorders (Osho et al., 2015).
Preliminary phytochemical screening of the flowers, stem bark and fruit was done by some researchers (Adeosun et al., 2012, 2013; Dai et al., 2013). Osho et al. (2015) mention that the ethyl acetate extract of the leaf indicates the presence of a mixture of non-polar aliphatic and aromatic compounds and polar hydroxyl aliphatic and aromatic compounds. However, the chemical composition of the analgesic and antiinflammatory activities of the leave extract of $C$. sebestena have not been studied to date. The isolation of the pure compounds of the bioactivity of individual compounds of the leaf extract will give much information about the medicinal values of this plant.

The $C$. sebestena ethyl acetate leaf extract has been shown to have antibacterial activity against Bacillus cereus and Staphylococcus aureus, as well as a relatively low toxicity profile in the liver of rats (Osho et al., 2015). The ethanolic 
extract of the whole plant of $C$. sebestena possesses significant hepatoprotective activity (Chandana et al., 2014), while C. sebestena root has anti-inflammatory and analgesic activities (Trivedi et al., 2017). The leaves of the plant possess anti-hyperglycemic properties in streptozotocin-induced diabetes, and it is hypolipidemic and a potent antioxidant (Sarathchandiran and Gnanavel, 2013). The essential oil of C. sebestena stem bark obtained through hydrodistillation was analysed using GC-MS, identifying a total of 19 compounds, including aliphatic hydrocarbons (72.73\%) and cyclic hydrocarbons (13.89\%). The essential oil is a potent antioxidant in vitro (Adeosun et al., 2013). Sebestenoids A-D (1-4) were isolated from bioassay-guided fractionation prepared from the $C$. sebestena fruit extract (Dai et al., 2013). The chloroform, ethyl acetate and methanol extract of $C$. sebestena root showed significant anti-inflammatory and analgesic activities at both dose levels of 100 and $200 \mathrm{mg} / \mathrm{kg}$ (Trivedi et al., 2017).

This study investigated the analgesic and anti-inflammatory activities of an ethanolic extract of $C$. sebestena $L$. cultivated in Indonesia. Analgesic activity was assessed using a hot plate method, acetic acid-induced writhing and formalin-induced paw licking. Anti-inflammatory activity was determined using carrageenan-induced rat paw oedema.

\section{MATERIALS AND METHODS}

\section{Plant materials}

Fresh leaves of $C$. sebestena in the flowering stage were collected in September 2018 from the Universitas Muhammadiyah Prof. Dr HAMKA regional, East Jakarta, Indonesia. The leaves were identified and authenticated taxonomically as Herbarium Bogorience, Bogor, Indonesia. A voucher specimen was deposited at the Pharmacognosy laboratory, Universitas Muhammadiyah Prof. Dr HAMKA as a record. The plant material was dried in the shade and ground to a coarse powder.

\section{Preparation of ethanol extract}

The dried powder $(2 \mathrm{~kg})$ was subjected to repeated extraction by maceration at room temperature with petroleum ether (60$80^{\circ} \mathrm{C}$ ) as a solvent for 2 days. The plant material was separated by filtration. The marc was dried and extracted continuously (two times, 2 days) with $1.5 \mathrm{~L}$ of dichloromethane (DCM; Merck, Germany) and filtered. The final marc was extracted with ethanol 70\% (Brataco, Indonesia) and concentrated by a vacuum evaporator (under reduced pressure). The percentage yield of the ethanol extract was $8.88 \% \mathrm{w} / \mathrm{w}$. The final $70 \%$ ethanol C. sebestena leaves extract (CSE) was used to evaluate the analgesic and anti-inflammatory activities.

\section{Animals}

Healthy male Wistar albino rats aged 8-9 weeks and weighing 180-200 g were obtained from the animal house, Faculty of
Veterinary, Bogor Agriculture Institute, Bogor. They were acclimatised to the laboratory conditions for 10 days before the studies, maintained in normal conditions and fed with standard pellet and water ad libitum. The room temperature was maintained at $25 \pm 1^{\circ} \mathrm{C}$, and the animals were kept under a $12 \mathrm{~h}$ light and dark cycle. The experimental protocol was approved by the Institutional Animal Ethical Committee of Universitas Prof. Dr HAMKA, Reg. no. 08/18.09/003. For all pharmacology experiments (analgesic, anti-inflammatory), male Wistar albino rats were used and divided into five groups of five animals each: Group I was the control group, Group II was the standard group treated with a standard drug (tramadol, Kimia Farma, Indonesia), Groups III, IV and V were treated with CSE at a dose of 100, 200 and $400 \mathrm{mg} / \mathrm{kg}$ orally, respectively, for 5 days. The extract and standard drug were given once a day between 08:00 and 09:00.

\section{Analgesic screening}

\section{Hot plate method}

The hot plate method was modified from those described by Ojewole (2006). Group I served as the control group and was orally administered $2 \mathrm{~mL}$ of $0.5 \%$ carboxymethyl cellulose (CMC) sodium (Na) suspension; Group II was treated with the standard drug tramadol $(5.14 \mathrm{mg} / \mathrm{kg}$ ) and Groups III, IV and V were treated with CSE at a dose of 100, 200 and $400 \mathrm{mg} / \mathrm{kg}$, respectively. All test samples were prepared by suspending in $0.5 \%$ CMC Na solution immediately before the start of the experiments. The animals were in a fasting condition for $12 \mathrm{~h}$ before starting the experiments. Rats were placed on a hot plate maintained at $55 \pm 1^{\circ} \mathrm{C}$. The responses were recorded in the form of jumping or licking of the paws, with the reaction time recorded at 15, 30, 45 and 60 min intervals after the administration of the treatments. A cut-off time of $30 \mathrm{~s}$ was selected to avoid tissue damage. Inhibition of hot plate paw-licking responses was expressed as the percentage of the maximal possible effect (\% MPE), calculated as:

$$
\% \mathrm{MPE}=T_{\mathrm{a}}-T_{\mathrm{b}} / T_{\mathrm{b}} \times 100
$$

where $T_{\mathrm{a}}$ and $T_{\mathrm{b}}$ represent the hot plate paw-licking latencies after and before the administration of test drug or vehicle, respectively.

\section{Writhing method}

The method described in Koster et al. (1959) was used. In this method, pain-causing acetic acid was injected in the peritoneal cavity, which induced writhing (abdominal pain and constrictions). Group I (the control group) was treated with $2 \mathrm{~mL}$ of $0.5 \%$ CMC Na suspension; Group II was treated with the standard drug acetylsalicylic acid intraperitoneal injection (i.p) given 15 min before i.p. injection of $0.75 \%$ acetic acid solution (Merck, Germany) and Groups III, IV and V were 
Table 1: Analgesic effects of CSE as determined by the hot plate method in rats

\begin{tabular}{|c|c|c|c|c|c|c|}
\hline \multirow{2}{*}{ Treatment } & \multirow{2}{*}{ Dose $(\mathbf{m g} / \mathbf{k g})$} & \multicolumn{5}{|c|}{ Time after drug administration } \\
\hline & & $0 \mathrm{~min}$ & $15 \mathrm{~min}$ & $30 \mathrm{~min}$ & $45 \mathrm{~min}$ & $60 \mathrm{~min}$ \\
\hline Control & --- & $2.32 \pm 1.36$ & $2.56 \pm 0.97$ & $2.26 \pm 1.11$ & $2.40 \pm 1.00$ & $1.66 \pm 0.61$ \\
\hline Tramadol & 5.14 & $2.54 \pm 0.69$ & $3.58 \pm 2.28$ & $3.44 \pm 1.74$ & $3.94 \pm 1.98$ & $\begin{array}{c}3.94 \pm 1.79^{b} \\
(57.87)\end{array}$ \\
\hline CSE & 100 & $5.00 \pm 1.17$ & $4.96 \pm 1.75^{\mathrm{a}}$ & $3.80 \pm 2.81$ & $2.70 \pm 0.89$ & $\begin{array}{c}3.34 \pm 2.13^{b} \\
(50.30)\end{array}$ \\
\hline CSE & 200 & $3.20 \pm 1.09$ & $5.16 \pm 2.02^{\mathrm{a}}$ & $4.24 \pm 0.66$ & $4.40 \pm 0.74$ & $\begin{array}{c}3.98 \pm 1.60^{\mathrm{b}} \\
(58.29)\end{array}$ \\
\hline CSE & 400 & $3.64 \pm 1.21$ & $5.52 \pm 1.98^{\mathrm{a}}$ & $4.20 \pm 2.44$ & $5.46 \pm 2.95$ & $\begin{array}{c}3.94 \pm 1.00^{\mathrm{b}} \\
(57.87)\end{array}$ \\
\hline
\end{tabular}

The latency for licking of the hind paw or jumping off from the surface was expressed as mean $\pm S E M,(n=5)$.

Values in brackets denote percentage of maximum possible effect (MPE) of the latency for licking of the hind paw or jumping off.

CSE, C. sebestena ethanol extract.

${ }^{a} p<0.05$ compared with the control.

${ }^{b} p<0.05$ compared with the control group.

treated orally with CSE at doses of 100,200 and $400 \mathrm{mg} / \mathrm{kg}$, respectively. Afterwards, the abdominal writhing was counted for $15,30,45$ and $60 \mathrm{~min}$, and the rate of inhibition of writhing was determined. The number of writhing and stretching was observed, recorded and expressed as percentage inhibition. The effectiveness of the treatment was evaluated by the decrease in the number of writhes compared with the control group. The percentage of inhibition of the number of writhing episodes was calculated as:

\%inhibiton rate $=\left(V-V_{\mathrm{t}}\right) / V \times 100 \%$,

where ' $V$ ' is the average number of stretching of control per group and ' $V$ ' is the average number of stretching of test per group.

\section{Anti-inflammatory screening}

\section{Carrageenan test}

Acute anti-inflammatory activity was evaluated by carrageenan-induced rat paw oedema as previously described by Turner et al. (1965). Male Wistar albino rats (150-200 g) maintained under environmental conditions had free access to standard diet and were fasted for $10 \mathrm{~h}$ before starting the experiments. Group I (the negative control group) was treated with $2 \mathrm{~mL}$ of $0.5 \%$ CMC Na suspension and diclofenac $\mathrm{Na}$ (Kimia Farma, Indonesia) $5 \mathrm{mg} / \mathrm{kg}$ was used as a standard control. The CSE (100, 200 and $400 \mathrm{mg} / \mathrm{kb})$ was administered to Groups III, IV and V. The treatment of Groups I, II, III, IV and V were given 30 min before carrageenan injection. At 30 min after sample administration, oedema was induced by injecting $0.1 \mathrm{~mL}$ of $1 \% \lambda$-carrageenan in sterile saline into the subplantar surface of the right hind paw. The paw volume was measured using a micrometre screw gauge at $0,1,2,3$ and $4 \mathrm{~h}$ after carrageenan injection and compared with the standard treated group. The anti-inflammatory effect was expressed as percentage inhibition of oedema:

Percentage inhibition $=\left(V_{\mathrm{t}}-V\right) / V_{\mathrm{t}} \times 100$, where $V$ is the volume of control and $V_{t}$ is the volume of the test.

\section{Statistical analysis}

The experimental data were expressed as mean \pm SEM. Data were analysed by one-way analysis of variance followed by Tukey, and the significance of the difference between means was determined when the values of $p<0.05$ were considered significant.

\section{RESULTS AND DISCUSSION}

Two different analgesic testing methods were employed to identify possible peripheral and central effects of the test substance. In this study, the analgesic reactivity to thermal stimuli in rats was assessed using the hot plate test, which is a sensitive acute pain test for detecting opiate analgesia. The hot plate test is a simple and sensitive method for studying analgesic and hyperanalgesic reactions in rats. Using the hot plate test, it was shown that oral administration of the ethanolic extract $(100,200$ and $400 \mathrm{mg} / \mathrm{kg})$ significantly prolonged the reaction time $15 \mathrm{~min}$ after treatment compared with the corresponding control groups (Table 1), and these effects were dose independent.

The analgesic effects of 100, 200 and $400 \mathrm{mg} / \mathrm{kg}$ of CSE were investigated. Table 1 presents the analgesic activity of the ethanol extract assessed using the hot plate. Tramadol showed no statistically significant increase in the reaction time, but there were significant differences in the thermal 
Table 2. Analgesic activity of CSE determined by the writhing test method

\begin{tabular}{|c|c|c|c|c|c|}
\hline \multirow{2}{*}{ Treatment } & \multirow{2}{*}{ Dose (mg/kg) } & \multicolumn{5}{|c|}{ Reaction time (min) } \\
\cline { 3 - 6 } & & $\mathbf{1 5}$ & $\mathbf{3 0}$ & $\mathbf{4 5}$ (\%inhibition) & $\mathbf{6 0}$ (\% inhibition) \\
\hline Control & -- & $68.6 \pm 10.64$ & $59.0 \pm 7.91$ & $56.2 \pm 6.87$ & $39.0 \pm 5.95$ \\
\hline Acetosal & 5.14 & $29.4 \pm 1.34$ & $23.8 \pm 3.70$ & $20.6 \pm 2.51(63.35)$ & $14.4 \pm 2.96(63.07)$ \\
\hline CSE & 100 & $38.6 \pm 7.02$ & $36.6 \pm 12.17$ & $36.0 \pm 14.31(35.94)$ & $31.2 \pm 10.89(20.00)^{\mathrm{a}}$ \\
\hline CSE & 200 & $32.6 \pm 7.02$ & $31.0 \pm 4.41$ & $29.0 \pm 3.74(48.40)$ & $25.4 \pm 2.61(34.87)^{\mathrm{a}}$ \\
\hline CSE & 400 & $33.2 \pm 4.86$ & $29.0 \pm 4.94$ & $27.8 \pm 1.48(50.53)$ & $22.2 \pm 5.93(43.08)^{\mathrm{a}}$ \\
\hline
\end{tabular}

The data were expressed as mean $\pm S E M,(n=5)$. Values in brackets denote the percentage of inhibition rate of the number of writhing.

CSE, C. sebestena ethanol extract.

${ }^{a} p<0.05$ compared with the positive group.

Table 3: Anti-inflammatory effects of CSE assessed by the carrageenan-induced rat paw oedema methodCSE, C. sebestena ethanol extract

\begin{tabular}{|c|c|c|c|c|c|c|}
\hline \multirow{2}{*}{ Treatment } & \multirow{2}{*}{ Dose $(\mathbf{m g} / \mathbf{k g})$} & \multicolumn{5}{|c|}{ Volume of hind paw ( $\mathrm{mm}$ ) } \\
\hline & & $\mathbf{O h}$ & $1 \mathrm{~h}$ & $2 \mathrm{~h}$ & $3 \mathbf{h}$ & $4 \mathrm{~h}$ \\
\hline Control & --- & $7.73 \pm 6.02$ & $13.18 \pm 0.72$ & $23.68 \pm 7.52$ & $25.68 \pm 1.91$ & $20.56 \pm 0.65$ \\
\hline $\begin{array}{l}\text { Diclofenac } \\
\text { sodium }\end{array}$ & 5 & $5.25 \pm 0.56$ & $10.01 \pm 6.56$ & $16.57 \pm 7.90$ & $\begin{array}{c}19.37 \pm 9.39 \\
(72.90)\end{array}$ & $\begin{array}{c}14.74 \pm 7.90 \\
(64.38)^{\mathrm{a}}\end{array}$ \\
\hline CSE & 100 & $6.26 \pm 0.58$ & $11.89 \pm 0.68$ & $23.51 \pm 0.92$ & $\begin{array}{c}24.78 \pm 9.39 \\
(74.74)\end{array}$ & $\begin{array}{c}16.86 \pm 7.90 \\
(61.32)^{\mathrm{a}}\end{array}$ \\
\hline CSE & 200 & $5.31 \pm 1.00$ & $10.02 \pm 6.56$ & $14.88 \pm 6.23$ & $\begin{array}{c}21.45 \pm 8.80 \\
(75.24)\end{array}$ & $\begin{array}{c}16.18 \pm 1.18 \\
(67.18)^{\mathrm{a}}\end{array}$ \\
\hline CSE & 400 & $5.53 \pm 0.85$ & $12.36 \pm 5.89$ & $18.51 \pm 0.68$ & $\begin{array}{c}23.69 \pm 0.93 \\
(76.66)\end{array}$ & $\begin{array}{c}16.46 \pm 6.30 \\
(66.40)^{\mathrm{a}}\end{array}$ \\
\hline
\end{tabular}

The values of paw oedema were expressed as mean $\pm S E M, n=5$. Values in brackets denote inhibition percentage of the oedema paw volume.

${ }^{a} p<0.05$ compared with the positive group.

stimulus observed in rats treated with the different doses of CSE compared with normal saline (negative control) throughout the $60 \mathrm{~min}$.

From Table 1, it is clear that oral administration of 100, 200 and $400 \mathrm{mg} / \mathrm{kg}$ of CSE significantly prolonged the reaction time 15 min after treatment in comparison with the control groups. Although the extracts appeared to induce higher analgesic activity in most cases, there was no consistent pattern of activity among the three extracts, that is, the effects were not dose dependent. The oral administration of ethanol extract of C. sebestena (100, 200 and $400 \mathrm{mg} / \mathrm{kg}$ ) significantly attenuated hot plate thermal stimulation.

In this study, the analgesic activity was evaluated through the hot plate and writhing assay in rats, whereas antiinflammatory activity was assessed via carrageenan-induced paw oedema in rats. Tissue damage or injury is associated with pain and inflammation. Analgesics can act on the peripheral or central nervous system. Peripherally acting analgesics act by blocking the generation of impulses of chemoreceptors at the site of pain, while centrally acting analgesics not only raise the pain threshold but also alter the physiological response to pain, suppressing animal anxiety and apprehension (Kumar et al., 2014).

The results presented in Table 2 show that 100, 200 and 400 $\mathrm{mg} / \mathrm{kg}$ of CSE exhibited significant $(\mathrm{p}<0.05)$ inhibition of the writhing compared with the standard drug (acetosal, 5.14 $\mathrm{mg} / \mathrm{kg}$ i.p). Indeed, CSE exerted a dose-dependent decrease in abdominal constriction in rats stimulated with $1 \%$ acetic acid solution. At $60 \mathrm{~min}$, the number of writhing of all extracts decreased significantly compared with the control. The oral administration of ethanol extract (100, 200 and $400 \mathrm{mg} /$ $\mathrm{kg}$ ) significantly attenuated the number of writhing in the writhing test method.

The acetic acid-induced writhing method is not only simple and reliable but also affords rapid evaluation of peripheral analgesic action. In this experiment, the animals react with characteristic stretching behaviour, which is called writhing. The abdominal constriction is related to the sensitisation of nociceptive receptors to prostaglandins (Victoria et al., 2012). In this model, pain is generated indirectly via endogenous 
mediators, such as bradykinin, serotonin, histamine, substance $P$ and $P G$ s which all act by stimulation of peripheral nociceptive neurons (Garcia, 2004). The ethanolic extract $(100,200$ and $400 \mathrm{mg} / \mathrm{kg}$ ) administered orally significantly inhibited the acetic acid-induced writhing in rats.

In the carrageenan-induced oedema test, a maximum oedema paw volume of $25.68 \pm 1.91$ and $20.56 \pm 0.65 \mathrm{~mm}$ (Table 3 ) was observed in the control rats, 3 and $4 \mathrm{~h}$ after the carrageenan injection. Administration of $\operatorname{CSE}(100,200$ and $400 \mathrm{mg} / \mathrm{kg}$ ) significantly $(\mathrm{p}<0.05)$ inhibited the development of pad swelling at $4 \mathrm{~h}$ after carrageenan injection. All doses of CSE were potent and produced anti-inflammatory effects similar to diclofenac $\mathrm{Na}$.

The oral administration of $\operatorname{CSE}(100,200$ and $400 \mathrm{mg} / \mathrm{kg}$ ) significantly attenuated the volume of carrageenan-induced oedema similar to diclofenac $\mathrm{Na}$, indicating that the ethanolic extract of $C$. sebestena leaves possesses anti-inflammatory activity.

This result has a similar effect to the previous research (Trivedi et al., 2017). It could be the phytochemical composition of the root that attributed the analgesic and anti-inflammatory properties the same as in the leaves. In this experiment, we did not explore the phytochemical components and could not find the reference of active ingredients from $C$. sebestena leaves that attributed the analgesic and anti-inflammatory properties.

Inflammation is a pathophysiological response of living tissue to injury that leads to the local accumulation of plasmatic fluid and blood cells. There are various components to an inflammatory reaction, such as oedema formation, leukocyte infiltration and granuloma formation that can contribute to the associated symptoms and tissue injury. Inflammation types are acute and chronic. The initial cardinal signs of inflammation include redness, heat, swelling, pain and loss of function (Trivedi et al., 2015, 2017). The carrageenan-induced oedema method has been commonly used as an experimental animal model for acute inflammation. This model is mainly mediated by histamine, serotonin and increased synthesis of prostaglandins in the damaged tissue, followed by prostaglandin release mediated by bradykinin, leukotrienes and polymorphonuclear cells (Kaushik, 2012). In this study, oral treatment with all the CSE doses significantly inhibited the paw oedema, suggesting that the anti-inflammatory actions of the ethanol extracts are related to inhibition of one or more intracellular signalling pathways involved with these mediator effects.

\section{CONCLUSION}

The present study demonstrated that the ethanol extract from C. sebestena leaves (100, 200 and $400 \mathrm{mg} / \mathrm{kg}$ ) possess significant potential to inhibit pain and suppress inflammation. The increase in dose is proportional to an increase in effect. However, further studies should be conducted to ensure efficacy and safety. The experiments could explore the fractions of the extract for further pharmacological and toxicological characterisation.

\section{CONFLICTS OF INTEREST}

The authors declare that they have no competing interests.

\section{ACKNOWLEDGEMENT}

All authors are grateful to the Dean of Faculty of Pharmacy and Sciences, Universitas Muhammadiyah Prof. Dr HAMKA Jakarta Indonesia, for providing necessary facilities and support to carry out the research work.

\section{References}

[1] Adeosun CB, Olaseinde S, Opeifa AO, Atolani O., Essential oil from the stem bark of Cordia sebestena scavenges free radicals. J. of Acute Medicine. 2013;(3): 138-141.

[2] Atolani O, Kayode OO, Adeniyi $\mathrm{O}$ and Adeosun CB. In vitro antioxidant potential of fatty acids obtained by direct transmethylation from fresh Cordia sebestena flowers. Annals of Tropical Research. 2014; 36(2): 104-114.

[3] Chandana R, Basini J, Reddy VJS., Hepatoprotective and antioxidant effect of Cordia sebestena in animal model. International J. of Pharmacology \& Toxicology. 2014;4(3): 181-189.

[4] Dai J, Sorribs A, Yoshida WY, Williams PG., Sebestenoids A-D, BACE1 inhibitors from Cordia sebestena. J. of Phytochemistry. 2013; 71 (17-18): 2168-2173.

[5] Garcia MD,Fernandez MA, Alvarez A, Saenz MT., Antinociceptive and anti-inflammatory effect of the aqueous extract from leaves of Pimenta racemosa var.ozua (Mirtaceae). J. Ethnopharmacol. 2004; (91): 69-73.

[6] Kaushik D,Kumar A, Kaushik P, Rana AC., Analgesic and anti-
Inflammatory activity of Pinus roxburghii Sarg.Advances inPharmacological Sciences. 2012; 1-6.

[7] Koster R, Andersons M, DeBeer E., Acetic acid analgesic screening. Federation Proceeding. 1959;(18): 418-420.

[8] Kumar CNS, Das A, Ray AGR., Anti-inflammatory activity of Sapindus laurifolius leaf extract in wistar rats. J. of Medicinal Plants Studies. 2014; 2 (1): 1-5.

[9] Ojewole, JAQ., Analgesic, anti-inflammatory and hypoglycaemic effects of ethanol extract of Zingiber officinale (Roscoe.) Rhizomes (Zingiberaceae) in mice and rats. Phytother. Res.2006; (20): 764772.

[10] Osho A, Otuechere CA, Adeosun CB, Oluwagbemi T and Atolani O. Phytochemical, sub-acute toxicity, and antibacterial evaluation of Cordia sebestena leaf extracts. J Basic Clin Physiol Pharmacol. 2015: 1-8.

[11] Sarathchandiran I and Gnanavel M., Investigation on hypoglycemic, antioxidant and hypolipidemic activity of ethanolic leaf extract of Cordia sebestena in Streptozotocin - 
Eur. Pharm. J. 2019, 66(2), 26-31.

\section{Evaluation of analgesic and anti-inflammatory activities of ethanolic extract of Cordia sebestena L.}

induced diabetic rat. International J. of Research in Pharmaceutical Sciences. 2013; 4 (3): 336-343.

[12] Trivedi MH, Ramana KV, and Rao CV., Anti-inflammatory and analgesic activities of Cordia monoicaRoxb.Stem. World J. of Pharmacy and Pharmaceutical Sciences. 2017; 6 (9): 1530 -1536.

[13] Trivedi MH, Ramana KV, Rao CV., Evaluation of antiinflammatory and analgesic activities of Cordia sebestena L. Roots. Indo American J. of Pharm. Research. 2015;5(08): 2765-2768.

[14] Turner RA., Screening Methods in Pharmacology. Academic Press Inc, London. 1965; 152.

[15] Victoria SH, Das S, Lalhlenmawia H, Phucho L, and Shantabi L., Study of analgesic, antipyretic and anti-inflammatory activities of the leaves of Thunbergia coccinea Wall. International Multidisciplinary Research J. 2012; 2 (2): 83-88. 